\title{
Levels of second hand smoke in pubs and bars by deprivation and food-serving status: a cross-sectional study from North West
} England

\author{
Richard Edwards*1, Christian P Hasselholdt ${ }^{2}$, Kim Hargreaves ${ }^{3}$, \\ Claire Probert ${ }^{4}$, Richard Holford ${ }^{5}$, Judy Hart ${ }^{6}$, Martie Van Tongeren ${ }^{7}$ and \\ Adrian FR Watson ${ }^{2}$
}

\begin{abstract}
Address: ${ }^{1}$ Department of Public Health, Wellington School of Medicine and Health Sciences, University of Otago, Wellington, New Zealand, ${ }^{2}$ Department of Environmental \& Geographical Sciences, Manchester Metropolitan University, Oxford Rd, Manchester, UK, ${ }^{3}$ East Lancashire Public Health Network, Eagle St, Accrington, UK, ${ }^{4}$ North West ASH, Silver St, Bury, UK, ${ }^{5}$ Manchester Public Health Development Service, Victoria Mill, Lower VickersStreet, Manchester, UK, ${ }^{6}$ Evidence for Population Health, Division of Epidemiology and Health Sciences, University of Manchester, Oxford Rd, Manchester, UK and ${ }^{7}$ Centre for Occupational and Environmental Health, Division of Epidemiology and Health Sciences, University of Manchester, Oxford Rd, Manchester, UK

Email: Richard Edwards* - Richard.Edwards@otago.ac.nz; Christian P Hasselholdt - houchez@hotmail.com; Kim Hargreaves - kim_m_hargreaves@yahoo.com.au; Claire Probert - claire.probert@burypct.nhs.uk; Richard Holford - richard.holford@northpct.manchester.nwest.nhs.uk; Judy Hart - judy.hart@manchester.ac.uk; Martie Van Tongeren - martie.j.van-tongeren@manchester.ac.uk; Adrian FR Watson - a.watson@mmu.ac.uk

* Corresponding author
\end{abstract}

Published: 22 February 2006

BMC Public Health 2006, 6:42 doi:10.1 186/147I-2458-6-42

This article is available from: http://www.biomedcentral.com/I47/-2458/6/42

(c) 2006 Edwards et al; licensee BioMed Central Ltd.

This is an Open Access article distributed under the terms of the Creative Commons Attribution License (http://creativecommons.org/licenses/by/2.0), which permits unrestricted use, distribution, and reproduction in any medium, provided the original work is properly cited.

\begin{abstract}
Background: The UK government proposed introducing partial smokefree legislation for England with exemptions for pubs and bars that do not prepare and serve food. We set out to test the hypothesis that pubs from more deprived areas and non food-serving pubs have higher levels of particulate air pollution.

Methods: We conducted a cross sectional study in four mainly urban areas of the North West of England. We recruited a stratified random sample of 64 pubs divided into four groups based on whether their local population was affluent or deprived (using a UK area based deprivation measure), and whether or not they served food. The timing of air quality monitoring stratified to ensure similar distribution of monitoring by day of the week and time of evening between groups. We used a portable air quality monitor to collect fine particle $\left(\mathrm{PM}_{2.5}\right)$ levels over a minimum of 30 minutes in areas where smoking was allowed,, and calculated mean time-time weighted average $\mathrm{PM}_{2.5}$ levels.

Results: Mean $\mathrm{PM}_{2.5}$ was $285.5 \mu \mathrm{g} / \mathrm{m}^{3}$ (95\% Cl 212.7 to 358.3). Mean levels in the four groups were: affluent food-serving pubs $(\mathrm{n}=16) 188.1 \mu \mathrm{g} / \mathrm{m}^{3}(95 \% \mathrm{Cl}$ I 28.1 to 248.1$)$; affluent non food-serving $(\mathrm{n}=16) 186.8 \mu \mathrm{g} / \mathrm{m}^{3}(95 \% \mathrm{Cl} \mathrm{I} 18.9$ to 254.3$)$; deprived food-serving $(\mathrm{n}=17) 399.4 \mu \mathrm{g} / \mathrm{m}^{3}(95 \% \mathrm{Cl} 177.7$ to 621.2$)$; and deprived non food-serving $(\mathrm{n}=15) 365.7 \mu \mathrm{g} / \mathrm{m}^{3}$ (195.6 to 535.7). Levels were higher in pubs in deprived communities: mean $383.6 \mu \mathrm{g} / \mathrm{m}^{3}(95 \% \mathrm{Cl} 249.2$ to 5 I 8.0 ) vs 187.4 $\mu \mathrm{g} / \mathrm{m}^{3}$ (I44.8 to 229.9$)$; geometric mean $245.2 \mu \mathrm{g} / \mathrm{m}^{3} \mathrm{vs} 15 \mathrm{I} .2 \mu \mathrm{g} / \mathrm{m}^{3}(\mathrm{p}=0.03)$. There was little difference in particulate levels between food and non food-serving pubs.

Conclusion: This study adds to the evidence that the UK government's proposals for partial smokefree legislation in England would offer the least protection to the most heavily exposed group - bar workers and customers in non foodserving pubs in deprived areas. The results suggest these proposals would work against the UK government's stated aim to reduce health inequalities.
\end{abstract}




\section{Background}

Second hand smoke (SHS) exposure causes of a range of serious adverse health effects in children, adults and pregnant women [1-3]. In the UK it is estimated that domestic exposure to secondhand smoke causes at least 3,600 deaths annually, while workplace exposure accounts for around 700 deaths per year

Internationally, the introduction of legislation to ensure workplaces and other public places are smokefree is a key current public health policy issue. In many countries and states, such as Ireland, New York, New Zealand and Norway, comprehensive smokefree legislation has been introduced. In the UK, Scotland and Northern Ireland propose to do the same. However, the UK government in its public health White Paper Choosing Health proposed introducing partial smokefree legislation for England with exemptions including for pubs and bars that do not prepare and serve food, and private members clubs [4].

A number of groups have criticised the logic of the partial exemption of pubs and bars as studies have shown that the highest levels of SHS exposure occur in pubs and bars [5-7]. The policy may also maintain or even increase differentials in ill health due to smoking as there is evidence that pubs and bars in more deprived areas are less likely to serve food and more likely to allow unrestricted smoking $[8,9]$.

We set out to test hypothesis that pubs and bars from more deprived areas and non food-serving pubs have higher levels of particulate air pollution.

\section{Methods \\ Setting and sampling}

The study was performed in four wholly or mainly urban Local Authority areas across the north west of England Burnley, Bury, Blackburn with Darwen, and Manchester. Each includes areas with relatively high levels of deprivation. The sampling frame for the study was the bars and pubs from the four study areas which had previously participated in a survey of North West hospitality premises [8]. We contacted pubs by letter and excluded those that did not wish to take part from the sampling frame. We also excluded town/city centre pubs as the area-based deprivation score is less likely to be representative of the socio-economic status of its customers. Finally, we excluded a number of pubs from the study during the data collection period as these were deemed to be too unsafe by the researchers.

Pubs were allocated an area-based deprivation score (Index of Multiple Deprivation [IMD] 2004 [10]) by mapping their postcode to the Census Super Output Area. Super Output Areas were categorised into deprivation quintiles (IMD 1 - 5) for all Super Output Areas across the North West. We identified four categories of pubs and bars. Firstly, we dichotomised pubs into affluent (IMD 13 ) and deprived (IMD 4 or 5). Secondly, we divided pubs into those which did and did not prepare and serve food based on their response in the earlier survey [8]. We aimed to recruit four pubs from each of the four categories in each study area (64 pubs in total). In order to maximise the contrast between the groups, for each study area and pub category we sampled randomly first from quintile 5 or 1 pubs in the sampling frame, then if necessary from quintile 4 or 2, and finally from quintile 3, stopping once four pubs plus 3-4 reserves were identified.

\section{Data collection}

We aimed to perform air quality measurements in four pubs per evening, one from each category, visited in sequence. To ensure a range of measurements we sampled on four separate days of the week (Tuesday-Friday). Pub occupancy may vary by day of the week and time of night. Therefore, we included a pub from each category on every evening and varied the order of monitoring the pubs so that a pub from each of the four categories was monitored once first, once second, once third and once fourth within each of the four study areas. Occasionally, to minimise transport time, the order of visiting pubs or choice of pubs had to be slightly modified from this plan.

Data collection was carried out using portable air quality monitors according to a protocol modified from one developed for a US study [11]. Pubs were visited unannounced by two or more investigators. The investigators carried a battery operated real time aerosol monitor (TSI SidePak AM510 Personal Aerosol Monitor - TSI, Inc., St. Paul, USA) in a small bag. The monitor was zero calibrated each evening. It was fitted with a $2.5 \mu \mathrm{m}$ impactor to sample and record the average levels of $\operatorname{RSP}\left(\mathrm{PM}_{2.5}\right)$ over one minute periods. The air flow rate was $1.7 \mathrm{l} / \mathrm{min}$. A length of Tygon ${ }^{\mathrm{TM}}$ tubing was attached to the inlet of the SidePak, with the other end left protruding outside the bag. The recorded measurements were downloaded to a PC for analysis. A calibration factor of 0.32 was applied based on calibration work with a ThermoMIE personalDataRAM model pDR-1200 real-time aerosol monitor (ThermoAndersen, Inc., Smyrna, GA, USA). This type of monitor had been used in a previous similar study in Delaware and has been calibrated against standard pumpand-filter gravimetric methods [12].

At each venue we identified the busiest room of the pub where smoking was allowed, and selected a central area for monitoring, away from any open external doors or windows, kitchen areas, and not in the immediate vicinity ( $<1$ metre) of anyone smoking (unless this were not possible). Smoke free areas or rooms were avoided. To avoid 


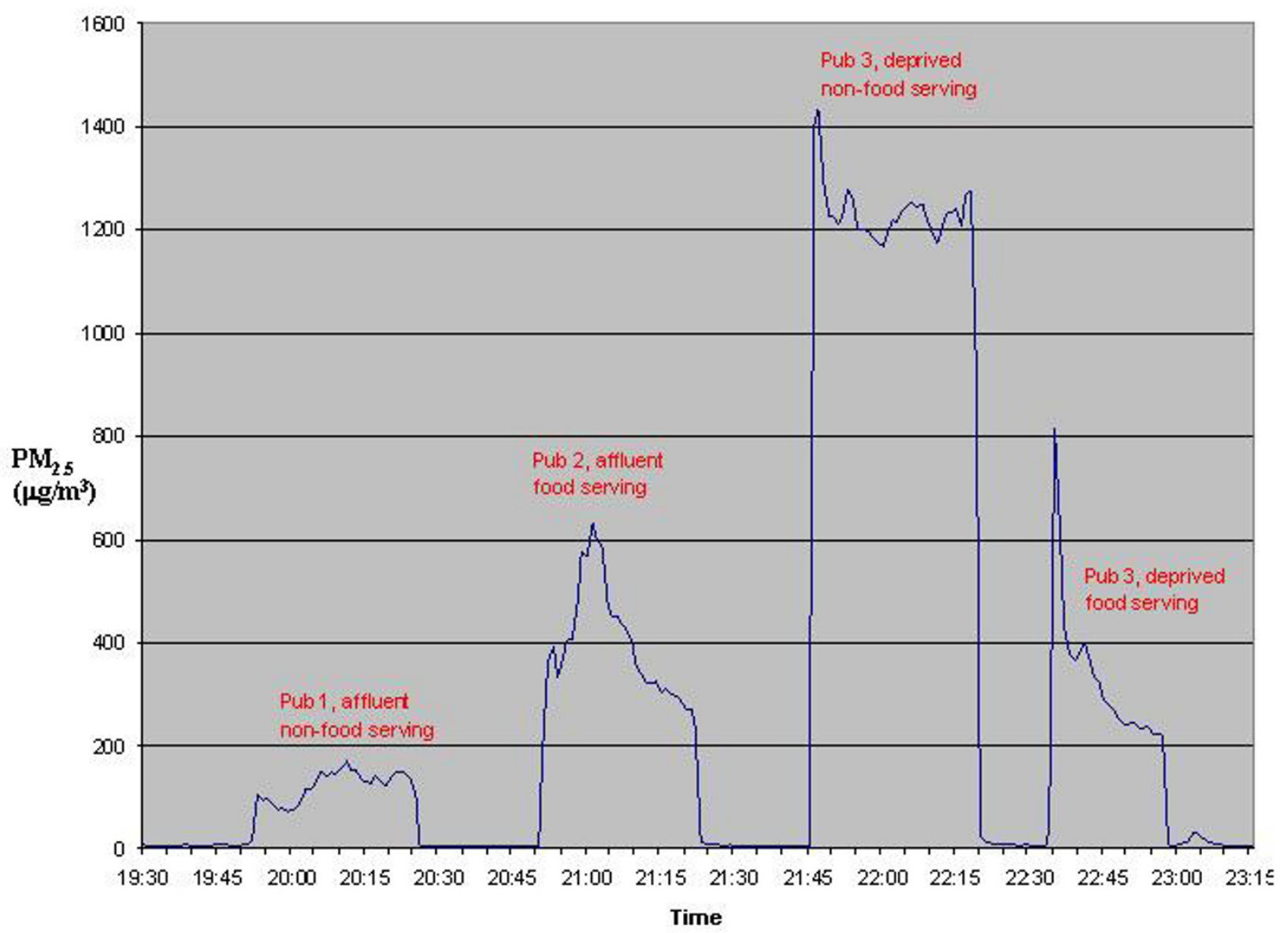

Figure I

Fine particle levels by pub category on one night's monitoring, September 2005.

affecting occupants' behaviour, investigators acted as normal customers and bought a drink before moving to the sampling area.

The bag was carried or placed on a seat or table wherever possible to sample the ambient air. We recorded the place of monitoring within the venue and time of entry. Recording occurred for at least 30 minutes and usually lasted about 30-35 minutes. We recorded whether or not special events likely to affect occupancy, such as quiz nights, were taking place.

\section{Analysis}

We calculated a time-weighted average $\mathrm{PM}_{2.5}$ level for each venue, and the mean $\mathrm{PM}_{2.5}$ levels by the four pub types and by deprivation and food-serving categories separately. $\mathrm{PM}_{2.5}$ levels generally had a highly positively skewed distribution, so significance tests were performed using log transformed data, and geometric means are also reported where appropriate.

\section{Ethics}

Ethical approval was not required for this study as no measurements were made on human subjects.

\section{Results}

Of 402 pubs in the sampling frame, $71 \%$ were in deprived areas (IMD4-5). Only nine refused to take part. Monitoring was completed in 64 pubs, 16 in each study area. Equal numbers from each pub category were sampled on each evening except for one night in Burnley when a foodserving pub from a deprived area was substituted for a non food-serving pub.

The mean time of starting monitoring by type of pub was as follows: affluent food-serving $8.58 \mathrm{pm}$ (range 7.15 to 
Table I: Fine particle $\left(\mathrm{PM}_{2.5}\right)$ levels by pub category in $\mu \mathrm{g} / \mathrm{m}^{3}$

\begin{tabular}{|c|c|c|c|}
\hline & Mean $(95 \% \mathrm{Cl})$ & Median & Range \\
\hline Affluent food-serving pubs $(n=16)$ & I88.I (128.I to 248.1$)$ & 160.3 & $59.3-424.4$ \\
\hline Affluent non food pubs $(n=16)$ & 186.6 ( 118.9 to 254.3$)$ & 163.7 & $14.9-497.4$ \\
\hline Deprived food-serving pubs $(n=17)$ & $399.4(177.7$ to 621.2$)$ & 329.8 & $54.1-1395.1$ \\
\hline Deprived non food pubs $(n=15)$ & 365.7 (195.6 to 535.7$)$ & 290.3 & $23.5-1226.6$ \\
\hline All affluent pubs $(n=32)$ & I 87.4 (| 44.8 to 229.9$)$ & 161.3 & $14.9-497.4$ \\
\hline All deprived pubs $(\mathrm{n}=32)$ & $383.6(249.2$ to 518.0$)$ & 312.4 & $23.5-1395.1$ \\
\hline All food-serving pubs $(n=33)$ & $293.6(172.1$ to 415.2$)$ & 166.7 & $54.1-1395.1$ \\
\hline All non food pubs $(n=3 I)$ & 277.3 (189.8 to 364.8$)$ & 216.6 & $14.9-1226.6$ \\
\hline
\end{tabular}

$10.50 \mathrm{pm}$ ); affluent non food-serving $9.17 \mathrm{pm}$ (range 7.50 to $10.40 \mathrm{pm}$ ); deprived food-serving $8.55 \mathrm{pm}$ (range 7.45 to $10.25 \mathrm{pm}$ ); deprived non food-serving $9.08 \mathrm{pm}$ (range 7.36 to $10.20 \mathrm{pm}$ ); and all affluent $9.08 \mathrm{pm}$ (range 7.15 to $10.50 \mathrm{pm}$ ) and all deprived $9.01 \mathrm{pm}$ (range 7.36 to $10.25 \mathrm{pm}$ ).

Figure 1 shows a typical plot from a single night's monitoring. It shows the dramatic increase in fine particle levels seen as we moved from the external ambient air and entered each pub. It also shows the variability in levels between pubs with the highest levels seen on this evening in the third pub, which was a non food-serving pub from a deprived area.

The mean level of $\mathrm{PM}_{2.5}$ across all venues was 285.5 (95\% CI 212.7 to 358.3$) \mu \mathrm{g} / \mathrm{m}^{3}$. Levels were highest on Thursdays (mean $\mathrm{PM}_{2.5}=356.7 \mu \mathrm{g} / \mathrm{m}^{3}$ ) and lowest on Tuesdays (mean $\mathrm{PM}_{2.5}=187.3 \mu \mathrm{g} / \mathrm{m}^{3}$ ). Mean levels varied by order of visit as follows: $287.3 \mu \mathrm{g} / \mathrm{m}^{3}$ for the first, $209.5 \mu \mathrm{g} / \mathrm{m}^{3}$ for the second, $311.6 \mu \mathrm{g} / \mathrm{m}^{3}$ for the third, and $333.4 \mu \mathrm{g} /$ $\mathrm{m}^{3}$ for the final visit.

Table 1 shows the mean, median and range of $\mathrm{PM}_{2.5}$ levels by pub category. Figure 2 shows these data graphically. The geometric mean for time weighted averages of $\mathrm{PM}_{2.5}$ were higher in pubs in deprived communities $(245.2 \mu \mathrm{g} /$ $\mathrm{m}^{3}, 95 \%$ CI 169.9 to $353.9 \mu \mathrm{g} / \mathrm{m}^{3}$ ) than in pubs in more affluent areas $\left(151.2 \mu \mathrm{g} / \mathrm{m}^{3} ; 95 \% \mathrm{CI} 116.4\right.$ to $196.4 \mu \mathrm{g} /$ $\left.\mathrm{m}^{3}\right), \mathrm{p}=0.03$. There was little difference in levels between food and non food-serving pubs (difference in geometric means $\left.=2.4 \mu \mathrm{g} / \mathrm{m}^{3}, \mathrm{p}=0.96\right)$.

\section{Discussion}

The English Public Health White Paper proposed to exempt non food-serving pubs and bars from the smokefree legislation. This study was designed to investigate air quality in pubs in relation to this proposal, and the degree to which air quality varied by deprivation. This is the first such investigation that we are aware of in the UK or elsewhere. We found that levels of fine particles were about twice as high in pubs situated in more deprived areas, but there was little difference between food and non foodserving pubs. Our measurements spanned a range of days and times, and included relatively quiet times early on in midweek evenings. We excluded Saturday nights, when occupancy and hence smoking levels are likely to be at their greatest. Despite this four pubs still had extremely high levels of $\mathrm{PM}_{2.5}$.

Fine particle levels have been used in previous studies of air quality in the workplace, including in the hospitality trade $[11,12]$. We found extremely high levels of $\mathrm{PM}_{2.5}$ in these hospitality venues, of the same order as those found in similar studies of 20 hospitality venues from New York (mean $324 \mu \mathrm{g} / \mathrm{m}^{3}$ ), [11] and eight hospitality venues from Delaware (mean $231 \mu \mathrm{g} / \mathrm{m}^{3}$ ) [12].

Levels of $\mathrm{PM}_{2.5}$ observed were much higher than seen in heavily trafficked urban areas. For example, mean ambient $\mathrm{PM}_{2.5}$ levels in central London (Marylebone Road) in September 2005 were $23.5 \mu \mathrm{g} / \mathrm{m}^{3}, 24.6 \mu \mathrm{g} / \mathrm{m}^{3}$ between 7 and $12 \mathrm{pm}$. [13] In the UK, there is no air quality standard for $\mathrm{PM}_{2.5}$, though one may be introduced soon. In the USA, the Environmental Protection Agency (EPA) uses an air quality standard for ambient air, one component of which is the mean $\mathrm{PM}_{2.5}$ level over a 24 hour period [14]. Levels over 65,150 and $250 \mu \mathrm{g} / \mathrm{m}^{3}$ are labelled by the EPA as 'unhealthy', 'very unhealthy' and 'hazardous' respectively [15]. Direct comparisons are only a rough guide as the EPA Air Quality Index refers to time weighted averages over a 24 hour period. However, using the EPA categorisation, air quality was unhealthy or worse in 57 out of 64 $(89 \%)$ of the pubs, and was hazardous in $26(41 \%)$. Of the pubs with hazardous levels $\left(>250 \mu \mathrm{g} / \mathrm{m}^{3}\right), 19$ were in deprived areas. All the pubs with very high levels - two $500-999 \mu \mathrm{g} / \mathrm{m}^{3}$ and four $>1000 \mu \mathrm{g} / \mathrm{m}^{3}$ - were in deprived areas.

A limitation of the study was the lack of information on ventilation in the participating pubs. However, the data represent current figures from real world settings and should therefore be representative of air quality experienced by customers and staff across a range of UK pubs. As 


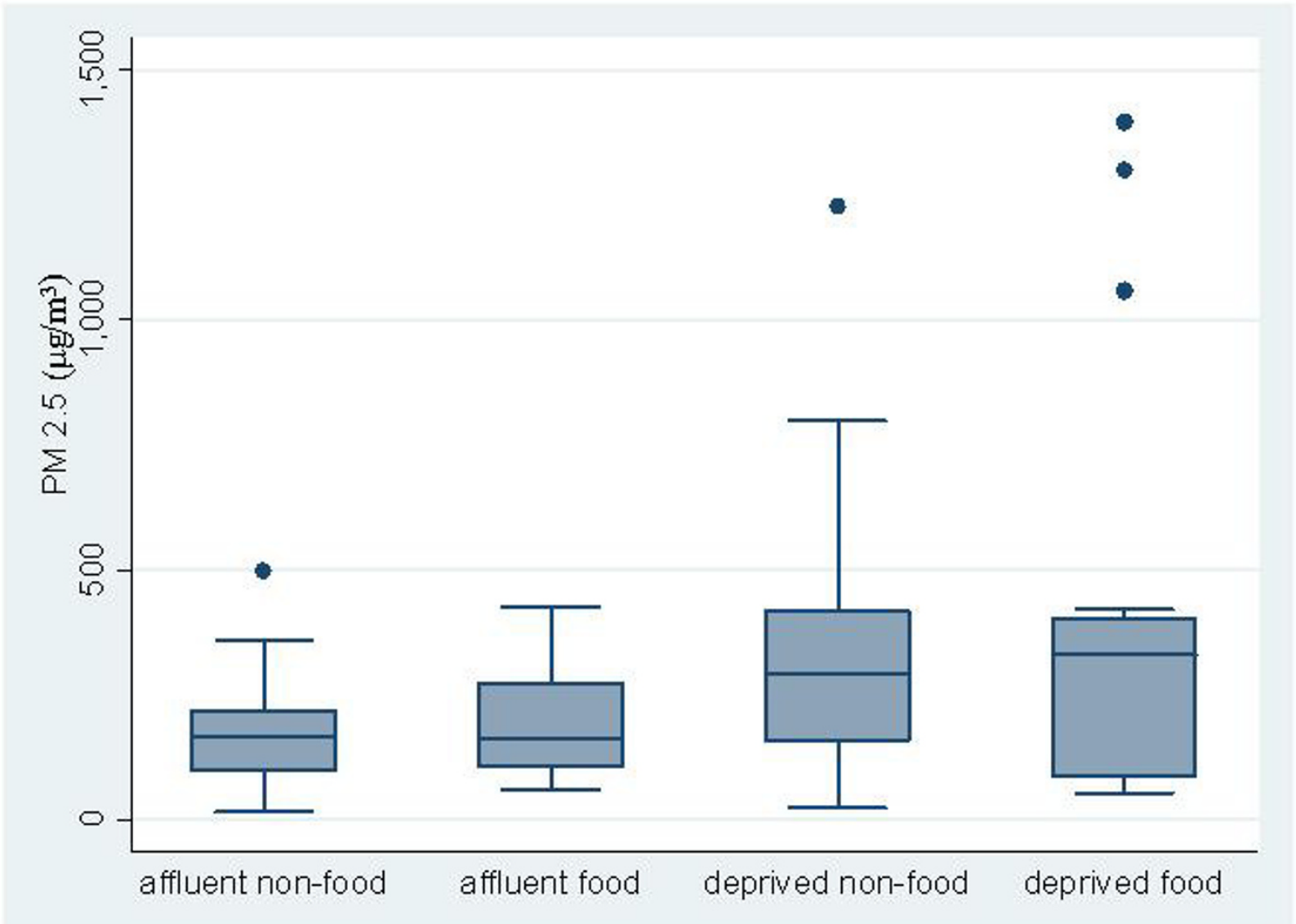

Figure 2

Box plots of fine particle levels by category of pub in $\mu g / \mathrm{m}^{3}$.

noted above, the lack of sampling on Saturday nights means that we may have missed periods when air quality is poorest. The very high levels of over $1000 \mu \mathrm{g} / \mathrm{m}^{3}$ seen in four pubs in our sample show how poor air quality can be in the smokiest venues.

\section{Conclusion}

In conclusion, we found high levels of fine particles in 64 pubs from across the north west of England. Air quality was poorest in pubs situated in more deprived areas. Most (86\%) pubs in the sampling frame from the four study areas were in IMD deprivation quintiles 3 to 5 , and $71 \%$ were in quintiles 4 or 5 . The equivalent figures were $82 \%$ and 65\% respectively in North West pubs from 15 Local Authority areas [8]. This suggests that the higher levels of SHS will be found in most pubs in the North West. Furthermore, the North West survey found that pubs which don't serve food, which will be exempt from the English Public Health White Paper smokefree legislation, will be concentrated in deprived areas [8]. Therefore, this study adds to the evidence that the UK government's proposals for partial smokefree legislation in the UK would offer the least protection to the most heavily exposed group - bar workers and customers in non food-serving pubs in deprived areas. This finding, together with the evidence that smokefree public places and workplaces are effective policies for reducing overall smoking prevalence, [16] suggest that the proposals for partial smokefree legislation are contrary to the UK government's stated aim to reduce health inequalities.

\section{Competing interests}

No specific funding was allocated to this study. Richard Edwards was unpaid chair of NW ASH and Claire Probert 
paid campaign director of NW ASH at the time of the study. All other authors have no competing interests to declare.

\section{Authors' contributions}

All authors contributed to developing the original idea for the study and the study protocol. Data collection was carried out principally by $\mathrm{CPH}, \mathrm{KH}, \mathrm{CP}$ and $\mathrm{RH}$ with additional help from the other authors. The dataset for analysis was prepared by RE, CPH and AFRW. Analysis was carried out mainly by RE with additional suggestions from AFRW and MvT. The paper was drafted by RE. All authors contributed comments on the first and subsequent drafts, and approved the final version for submission. RE is the guarantor of the study.

\section{Acknowledgements}

Thanks to Andy Hyland and Mark Travers of the Roswell Park Cancer Institute, Buffalo for providing the equipment for the study, access to their data collection protocol, and providing training in measuring particulates in pubs using the SidePak monitor.

\section{References}

I. International Agency on Research on Cancer: Tobacco Smoke and Involuntary Smoking Lyon: International Agency on Research on Cancer; 2004.

2. Scientific Committee on Tobacco and Health: Report of the Scientific Committee on Tobacco and Health London: The Stationery Office; 1998.

3. Tobacco Advisory Group of the Royal College of Physicians: Going smoke-free: the medical case for clean air in the home, at work and in public places London: Royal College of Physicians of London; 2005.

4. Department of Health: Choosing health: making healthier choices easier London: Stationary Office; 2004.

5. Jarvis M: Quantitative survey of exposures to other people's smoke in London bar staff London: Department of Epidemiology and Public Health, University College London; 200I.

6. Jarvis MJ, Foulds J, Feyerabend C: Exposure to passive smoking among bar staff. BrJAddict 1992, 87(I): I I I-II3.

7. Siegel M, Skeer $M$ : Exposure to secondhand smoke and excess lung cancer mortality risk among workers in the "5B's": bars, bowling alleys, billiard halls, betting establishments, and bingo parlours. Tobacco Control 2003, I 2:333-338.

8. Tocque K, Edwards R, Fullard B: The impact of partial smokefree legislation on health inequalities? Evidence from a survey of I I50 pubs in North West England. BMC Public Health 2005, 5:9I.

9. Woodall A, Sandbach E, Woodward C, Aveyard P, Merrington G: The partial smoking ban in licensed establishments and health inequalities in England: modelling study. British Medical Journal 2005, 33 I:488-489.

10. Office of the Deputy Prime Minister: The English Indices of Deprivation 2004: Summary (revised) London: The Stationery Office; 2004.

II. Travers M, Cummings KM, Hyland A, Repace J, Pechacek TF, Caraballo R, Babb S: Indoor air quality in hospitality venues before and after the implementation of a Clean Indoor Air Law Western New York, 2003. Morb Mortal Wkly Rep 2004, 53(44): I038-|04I.

12. Repace J: Respirable particles and carcinogens in the air of Delaware hospitality venues before and after a smoking ban. Journal of Occupational \& Environmental Medicine 2004, 46:887-905.

13. UK National Air Quality Archive [http://www.airquality.co.uk/ archive/]

14. National Ambient Air Quality Standards (NAAQS) [http:// www.epa.gov/air/criteria.html]

15. National Ambient Air Quality Index [http://airnow.gov/ index.cfm?action=static.aqi]
16. Fichtenberg CM, Glantz SA: Effect of smoke-free workplaces on smoking behaviour: systematic review. BMJ 2002, 325:188-194.

\section{Pre-publication history}

The pre-publication history for this paper can be accessed here:

http://www.biomedcentral.com/1471-2458/6/42/prepub
Publish with Biomed Central and every scientist can read your work free of charge

"BioMed Central will be the most significant development for disseminating the results of biomedical research in our lifetime. " Sir Paul Nurse, Cancer Research UK

Your research papers will be:

- available free of charge to the entire biomedical community

- peer reviewed and published immediately upon acceptance

- cited in PubMed and archived on PubMed Central

- yours - you keep the copyright

Submit your manuscript here:

http://www.biomedcentral.com/info/publishing_adv.asp
BioMedcentral 